\title{
Características físico-químicas e celulares do leite de cabras Saanen, Alpina e Toggenburg*
}

\section{Physicochemical and cellular characteristics of milk from Saanen, Alpine and Toggenburg goats}

\author{
Karina Medici Madureira, ${ }^{* *}$ Viviani Gomes, ${ }^{* \star *}$ Wanderley Pereira de Araújo†
}

\begin{abstract}
Resumo
O objetivo do presente trabalho foi determinar as características físico-químicas e celulares em 103 amostras de leite provenientes das cabras Saanen, Alpina e Toggenburg, em lactação, realizando-se, para tanto, a contagem eletrônica e microscópica de células somáticas, e a mensuração dos teores de gordura, proteína, lactose e sólidos totais. Os valores medianos da contagem celular eletrônica e microscópica foram de 406.000 e 142.840 células $/ \mathrm{mL}$ de leite, respectivamente. Comparando-se as raças, verificou-se que a Toggenburg apresentou uma maior contagem celular automática (556.000 céls $/ \mathrm{mL}$ ), quando comparada às raças Saanen (152.000 céls $/ \mathrm{mL}$ ) e Alpina $(218.000$ céls $/ \mathrm{mL})$. Não houve diferença na contagem microscópica entre as raças. Os valores medianos de proteína $(2,98 ; 3,10$ e 3,02 $\mathrm{g} / \mathrm{dL})$ e sólidos totais $(10,91 ; 11,41$ e 11,22 g/dL) não apresentaram diferenças entre as raças Saanen, Alpina e Toggenburg, respectivamente. O valor mediano de gordura obtido para raça Saanen $(2,35 \mathrm{~g} /$ $\mathrm{dL})$ foi menor que da Toggenburg $(3,13 \mathrm{~g} / \mathrm{dL})$; em contrapartida, o teor de lactose foi menor na raça Toggenburg $(4,06 \mathrm{~g} / \mathrm{dL})$. Os parâmetros físico-químicos sofreram variações de acordo com as raças estudadas, verificadas pela menor concentração de gordura em cabras Saanen; maior celularidade e menor teor de lactose em cabras Toggenburg.
\end{abstract}

Palavras-chave: caprinos, componentes, contagem de células somáticas, qualidade.

\begin{abstract}
The objective of this study was to determine the physicochemical and cellular characteristics in 103 milk samples from goats Saanen, Alpine and Toggenburg, lactating, performing the electronic and microscopic somatic cells count, and measurement of fat, protein, lactose and total solids levels. The median values of the electronic and microscopic counts were respectively 406,000 and $142,840 \mathrm{cell} / \mathrm{s} / \mathrm{m}$ of milk. Comparing the breeds, it was found that the Toggenburg had a higher automatic cell count $(556,000$ cells $/ \mathrm{mL}$ ) compared to Saanen $(152,000$ cells $/ \mathrm{mL})$ and Alpine $(218,000$ cells $/ \mathrm{mL})$. There was no difference in the microscopic count between breeds. Median values of protein $(2.98,3.10$ and $3.02 \mathrm{~g} / \mathrm{dL})$ and total solids $(10.91 ; 11.41$ and $11.22 \mathrm{~g} / \mathrm{dL})$ did not differ between Saanen, Alpine and Toggenburg, respectively. The median value obtained for fat from Saanen ( $2.35 \mathrm{~g} / \mathrm{dL})$ was lower than the Toggenburg ( $3.13 \mathrm{~g} / \mathrm{dL})$, in contrast, the lactose content was lower in the Toggenburg breed $(4.06 \mathrm{~g} / \mathrm{dL})$. The physicochemical parameters have varied according to the breeds studied, verified by the lowest concentration of fat in Saanen goats; greater cellularity and lower lactose content in Toggenburg goats.
\end{abstract}

Keywords: caprine, components, somatic cell count, quality.

\section{Introdução}

O leite de cabras possui características nutritivas que o torna um alimento indicado por médicos para diversos setores da população: crianças, idosos e indivíduos alérgicos ao leite de vaca (Wang et al., 2015). A crescente demanda por derivados lácteos tem exigido a melhoria do produto final, por meio da introdução de tecnologias e melhoramento genético das raças (Garcia et al., 2014; Pisanu et al., 2013).

O leite caprino apresenta algumas particularidades, como menores glóbulos de gordura (2-3 $\mu \mathrm{m})$ e ausência da substância aglutinina, que colaboram para o aumento na sua digestibilidade, além da menor concentração da porção as1 da caseína (20\%), que minimiza problemas alérgicos em humanos (Pisanu et al., 2013).

A secreção glandular do tipo apócrina nas cabras promove a liberação de partículas citoplasmáticas no leite, geralmente anucleadas, porém algumas destas estruturas podem conter grande quantidade de RNA e proteínas, além de possuírem tamanhos similares às células somáticas (Madureira et al., 2010). Assim, o uso de métodos de contagem padronizados para vacas pode elevar aparentemente a celularidade do leite caprino (Garcia et al., 2014).

*Recebido em 15 de julho de 2015 e aceito em 29 de julho de 2017

**Universidade Federal da Bahia, Escola de Medicina Veterinária e Zootecnia, Departamento de Anatomia, Patologia e Clínicas Veterinárias, Salvador, Bahia, Brasil e-mail: karina.madureira@ufba.br. *Autor para correspondência.

***Universidade de São Paulo, Faculdade de Medicina Veterinária e Zootecnia, Departamento de Clínica Médica, São Paulo, São Paulo, Brasil. 
No Brasil, os requisitos mínimos de qualidade do leite de cabra foram estabelecidos na Instrução Normativa (IN) $n^{\circ} 37$, onde foram fixados os valores de 0,6 a $2,9 \%$ para gordura; teores mínimos de 2,8\% para proteína; $4,3 \%$ para lactose e $8,2 \%$ para sólidos totais (Brasil, 2000). Contudo, a contagem de células somáticas (CCS) não foi adotada como parâmetro de avaliação da qualidade do leite, pelas variações decorrentes da fase da lactação (Gomes et al., 2004; Paape et al., 2007; Queiroga et al., 2007); parto (Paape et al., 2007); raças (Sung et al., 1999; Paape et al., 2007) e condições climáticas (Paape et al., 2007).

Pesquisas nacionais e internacionais têm apresentado diferentes valores para os parâmetros físico-químicos do leite de cabras Saanen, raça mais estudada por ser difundida mundialmente (Prata et al., 1998; Sung et al., 1999; Queiroga et al., 2007), porém essas pesquisas são pouco representativas à caprinocultura nacional considerando-se a inserção de outras raças no sistema produtivo.

Conhecer os valores dos componentes lácteos de diferentes raças caprinas é uma forma de avaliar a adequação do leite ao processamento pelos laticínios e elaboração de programas de qualidade, agregando valor econômico ao produto final. Portanto, o objetivo do presente trabalho foi determinar as características físico-químicas e celulares do leite de cabras das raças Saanen, Toggenburg e Alpina.

\section{Material e métodos}

Foram selecionadas quatro fazendas localizadas no estado de São Paulo, que continham as principais raças exploradas para a produção leiteira. Destas, duas mantinham criações mistas com animais das raças Saanen, Alpina e Toggenburg, porém, as outras duas criavam somente Saanen ou Alpina. Todas elas apresentavam sistema de produção intensivo, no qual era fornecido aproximadamente $1 \mathrm{~kg}$ de ração comercial ao dia, contendo o mínimo de $20 \%$ de proteína bruta, além de forragens diversas e sal mineral para caprinos.

Foram triadas 57 cabras soronegativas ao vírus da artrite encefalite caprina (CAEV), em lactação (15 até 300 dias pósparto) e diferentes números de parições.

Inicialmente foi avaliada a saúde da glândula mamária conforme preconizado por Smith e Sherman (2009). Em seguida, os tetos foram higienizados com solução clorada a $2 \%$ e secos com papel-toalha individual, para colheita de três alíquotas das amostras de leite de cada metade mamária. O material obtido foi transportado para o laboratório sob refrigeração.

A primeira alíquota $(40 \mathrm{~mL})$ foi colhida em frasco plástico contendo bronopol (2-bromo-2nitropropane-1,3-diol) para a determinação da CCS eletrônica e avaliação dos parâmetros químicos do leite, utilizando-se as técnicas de citometria de fluxo e leitura de absorção infravermelha respectivamente, no equipamento Somacount $300^{\circledR}$ (Bentley Instruments Inc.).

A segunda alíquota ( $3 \mathrm{~mL})$ foi usada para confecção de esfregaços lácteos segundo a técnica de Prescott e Breed (1910). As lâminas foram fixadas em solução de Carnoy's e coradas com solução de verde de metil e pironina-Y (Zeng, 1996).

A terceira alíquota $(2 \mathrm{~mL})$ destinada ao exame bacteriológico foi obtida imediatamente após o término das etapas anteriores, após desinfecção dos tetos com algodão embebido em solução de álcool $70 \%$. Estas alíquotas foram semeadas em ágar sangue de ovino a $5 \%$, e incubadas a $37^{\circ} \mathrm{C}$ durante 24 a 72 horas, para identificação e exclusão das amostras positivas. (Murray et al., 1999).

Os resultados foram avaliados pelo paquete estatístico SAS, versão 2001 para Windows (Sas, 2001). Como a CCS e os constituintes físico-químicos do leite (gordura, proteína, lactose e sólidos totais) apresentaram distribuição não paramétrica, os resultados foram apresentados em valores medianos, sendo comparados estatisticamente pelo teste de Kruskal-Wallis.

\section{Resultados e discussão}

As características físico-químicas e celulares do leite de cabras das raças Saanen, Toggenburg e Alpina foram apresentadas na Tabela 1.

A mastite foi detectada em 11/114 (9,64\%) das metades mamárias provenientes das 57 cabras previamente selecionadas, determinada pela presença de sinais inflamatórios verificados no exame físico, associado ao crescimento bacteriano de micro-organismos patogênicos. Desta forma, 11 amostras foram excluídas desta investigação, avaliando-se, portanto, os parâmetros físico-químicos das amostras de leite provenientes de 103 metades mamárias, correspondentes a 15 cabras da raça Alpina, 33 Toggenburg e 55 Saanen.

O valor mediano da CCS eletrônica (406.000 células $/ \mathrm{mL}$ ) obtido no presente trabalho foi semelhante ao valor de 478.000 células/ $\mathrm{mL}$ obtido por Persson e Olofsson (2011) e encontra-se dentro do intervalo de 270.000 a 2.000 .000 células $/ \mathrm{mL}$ de leite determinado por Paape et al. (2001) como sendo o valor de referência para o leite de cabras livres de infecção mamária.

Os valores medianos obtidos para a CCS eletrônica (406.000 células $/ \mathrm{mL}$ ) e microscópica direta (142.840 células $/ \mathrm{mL})$ foram significantemente diferentes $(p<0,0001)$. $O$ método eletrônico tem sido usado para a CCS do leite de vaca no Programa Nacional de Qualidade do Leite, porém, o uso de equipamentos não calibrados com leite caprino pode aumentar em até $27,3 \%$ o valor dessa contagem (Zeng, 1996). Entretanto, o método padrão usando-se a contagem microscópica apresenta limitações de uso em larga escala, devido ao tempo dispendido para execução das análises; além disso, a secreção láctea do tipo apócrina das cabras exige a diferenciação entre partículas citoplasmáticas anucleadas das células somáticas liberadas durante o processo de produção de leite, por meio da utilização de corantes nucleares, como a pironina- $Y$ (Madureira et al., 2010). Diante destes entraves, estratégias como a utilização de técnicas de contagens celulares DNA-específicas vêm sendo estudadas, possibilitando a determinação das diferentes proporções leucocitárias presentes no leite caprino e garantindo assim uma melhor acurácia do estado imunológico da glândula mamária (Boulaaba et al., 2011; Souza et al., 2012).

Com relação à contagem microscópica direta, o resultado obtido (142.840 células $/ \mathrm{mL}$ ) foi menor que o obtido por Andrade et al. (2001) (1.163.000 células/mL), porém neste trabalho foi utilizado o corante azul de metileno para coloração dos esfregaços lácteos, método não recomendado para a espécie caprina por não excluir a mensuração das partículas citoplasmáticas. 
Tabela 1: Contagens de células somáticas e composição química do leite de fêmeas caprinas das raças Saanen, Alpina e Toggenburg

\begin{tabular}{|c|c|c|c|c|c|c|}
\hline \multirow{2}{*}{ Parâmetros } & & \multicolumn{3}{|c|}{ Raças } & \multirow{2}{*}{$\begin{array}{l}\text { Mediana } \\
\text { Geral }\end{array}$} & \multirow[b]{2}{*}{ Significância } \\
\hline & & $\begin{array}{c}\text { Saanen } \\
(n=55)\end{array}$ & $\begin{array}{l}\text { Alpina } \\
(n=15)\end{array}$ & $\begin{array}{c}\text { Toggenburg } \\
(n=33)\end{array}$ & & \\
\hline \multirow{3}{*}{$\begin{array}{c}\text { CCS } \\
\text { automática } \\
\text { (céls } / \mathrm{mL} \text { ) }\end{array}$} & Mediana & $152.000^{\mathrm{b}}$ & $218.000^{b}$ & $556.000^{a}$ & \multirow{3}{*}{406.000} & \multirow{3}{*}{$p=0,0073$} \\
\hline & Mínimo & 10.000 & 25.000 & 40.000 & & \\
\hline & Máximo & 8.431 .000 & 1.719 .000 & 5.542 .000 & & \\
\hline \multirow{3}{*}{$\begin{array}{c}\text { CCS } \\
\text { microscópica direta } \\
\text { (céls } / \mathrm{mL})\end{array}$} & Mediana & 69.635 & 107.130 & 160.695 & \multirow{3}{*}{142.840} & \multirow{3}{*}{$p=0,4956$} \\
\hline & Mínimo & 3.571 & 14.284 & 7.142 & & \\
\hline & Máximo & 889.179 & 1.174 .859 & 5.049 .394 & & \\
\hline \multirow{3}{*}{$\begin{array}{l}\text { Gordura } \\
\text { (g/dL) }\end{array}$} & Mediana & $2,35^{b}$ & $2,19^{a b}$ & $3,13^{a}$ & \multirow{3}{*}{2,65} & \multirow{3}{*}{$p=0,0147$} \\
\hline & Mínimo & 0,65 & 1,27 & 1,43 & & \\
\hline & Máximo & 9,65 & 3,43 & 4,53 & & \\
\hline \multirow{3}{*}{$\begin{array}{l}\text { Proteína } \\
\text { (g/dL) }\end{array}$} & Mediana & 2,98 & 3,10 & 3,02 & \multirow{3}{*}{3,02} & \multirow{3}{*}{$p=0,4102$} \\
\hline & Mínimo & 2,33 & 2,71 & 2,55 & & \\
\hline & Máximo & 3,83 & 3,94 & 3,68 & & \\
\hline \multirow{3}{*}{$\begin{array}{l}\text { Lactose } \\
\text { (g/dL) }\end{array}$} & Mediana & $4,61^{a}$ & $4,62^{a}$ & $4,06^{b}$ & \multirow{3}{*}{4,40} & \multirow{3}{*}{$p<0,0001$} \\
\hline & Mínimo & 4,01 & 4,16 & 3,84 & & \\
\hline & Máximo & 5,40 & 5,07 & 4,29 & & \\
\hline \multirow{3}{*}{$\begin{array}{l}\text { Sólidos totais } \\
\qquad(\mathrm{g} / \mathrm{dL})\end{array}$} & Mediana & 10,91 & 11,41 & 11,22 & \multirow{3}{*}{11,10} & \multirow{3}{*}{$p=0,9244$} \\
\hline & Mínimo & 9,89 & 9,16 & 9,52 & & \\
\hline & Máximo & 40,65 & 12,27 & 13,02 & & \\
\hline
\end{tabular}

Letras minúsculas distintas na mesma linha indicam diferenças estatísticas entre si - $(p<0,05)$.

Em relação à raça, Toggenburg apresentou celularidade $(556.000$ céls $/ \mathrm{mL})$ significativamente maior $(P<0,05)$ que a raça Saanen (152.000 céls $/ \mathrm{mL})$ e Alpina (218.000 céls $/ \mathrm{mL})$ para a CCS eletronica. Por outro lado, não foi observada diferença significativa $(P>0,05)$ entre as raças, utilizando-se o método microscópico.

Vilanova et al. (2008) determinaram a CCS automática em cabras da raça Saanen criadas no Rio Grande do Sul e obtiveram o valor mediano de 645.000 células $/ \mathrm{mL}$ de leite, superior ao obtido nesta pesquisa (406.000 células $/ \mathrm{mL}$ ). O estado de higidez da glândula mamária não foi relatado pelos respectivos autores e as infecções mamárias provocadas por bactérias e pelo CAEV podem elevar a CCS do leite, pela migração de leucócitos mono e polimorfonucleares da circulação sanguínea para o foco infeccioso (Souza et al., 2012). Além disso, as variáveis clima e sistema de criação podem justificar as diferenças entre as contagens celulares obtidas no citado e no presente trabalho (Paape et al., 2007; Queiroga et al., 2007).

O teor de gordura foi o constituinte lácteo que apresentou maiores oscilações considerando-se as raças avaliadas. A raça Saanen apresentou valor mediano significativamente menor de gordura no leite $(2,35 \mathrm{~g} / \mathrm{dL})$, quando comparada à raça Toggenburg $(3,13$ $\mathrm{g} / \mathrm{dL}$ ) e tem sido apontada como a raça produtora de leite com menor teor de gordura (Sung et al., 1999). Resultados similares foram encontrados por outros pesquisadores, variando de 2,55 $\mathrm{g} / \mathrm{dL}$ em cabras Saanen a 3,55 g/dL na Toggenburg (Sung et al., 1999), e 4,10 g/dL encontrado para a raça Saanen (Gomes et al., 2004). Outro fator que influenciou nos resultados foi a composição da dieta, uma vez que o delineamento experimental não permitiu a homogeneização da dieta fornecida aos animais. Além disso, características genéticas vinculadas à raça podem ter interferido nestes parâmetros (Pisanu et al., 2013).

Os precursores da gordura do leite são os triglicerídeos presentes na circulação sanguínea dos ruminantes, que são produzidos a partir dos ácidos graxos voláteis (AGV), especialmente ácido acético e butírico, sintetizados no rúmen devido ao consumo de forragem (Silva et al., 2011). Assim, a diminuição do consumo e da qualidade da forragem podem acarretar diminuição dos teores de gordura do leite (Sanz Sampelayo et al., 2007; Zervas e Tsiplakou, 2011). Desta forma, acredita-se que o fator dieta pode ter contribuído com as oscilações observadas nesta pesquisa, pois a dieta total dos animais não foi padronizada devido à disponibilidade de diferentes alimentos em cada criação.

Os valores medianos de proteína não apresentaram diferenças entre as raças Saanen, Alpina e Toggenburg (2,98; 3,10 e 3,02 $\mathrm{g} / \mathrm{dL}$, respectivamente), assim como os de sólidos totais $(10,91$, 11,41 e 11,22 g/dL, respectivamente). Poucas oscilações nos valores de proteína foram verificados na literatura, no qual foram relatados valores mínimos para animais da raça Alpina - 3,08g/ $\mathrm{dL}$, seguida das raças Saanen e Toggenburg - 3,25 e 3,21 g/dL, existindo diferença significativa somente entre as raças Alpina e Saanen (Sung et al., 1999). Prata et al. (1998) estudaram a raça Saanen e encontraram valor médio de proteína de 3,27g/ $\mathrm{dL}$, similar também ao obtido neste trabalho.

Com relação aos teores de lactose, a raça Toggenburg apresentou valores significativamente menores $(4,06 \mathrm{~g} / \mathrm{dL})$ do 
que as raças Saanen $(4,61 \mathrm{~g} / \mathrm{dL})$ e Alpina $(4,62 \mathrm{~g} / \mathrm{dL})$. Sung et al. (1999) também encontraram menores valores para Toggenburg $(4,16 \mathrm{~g} / \mathrm{dL})$ em relação às raças Saanen $(4,56 \mathrm{~g} / \mathrm{dL})$ e Alpina $(4,37 \mathrm{~g} / \mathrm{dL})$. A lactose é o componente químico mais estável do leite e está diretamente relacionada à regulação da pressão osmótica, de modo que uma maior produção de lactose determina uma maior produção de leite. Além disso, o teor de lactose no leite pode ser influenciado pela quantidade de concentrado disponibilizado na dieta (Queiroga et al., 2007). Apesar de no presente trabalho não ter ocorrido o controle da produção leiteira, os menores teores de lactose da raça Toggenburg sugerem uma menor produção de leite.

Considerando as concentrações mínimas exigidas pela legislação brasileira (Brasil, 2000), como requisitos de qualidade do leite caprino $(0,6$ a 2,9\% para gordura; teores mínimos de 2,8\% para proteína; 4,3\% para lactose e $8,2 \%$ para sólidos totais) pôde-se verificar neste trabalho, que as três raças aqui estudadas se enquadram nestes parâmetros de qualidade

\section{Referências}

ANDRADE, P.V.P.; SOUZA, M.R.; BORGES, I.; PENNA, C.F.A.M. Contagem de células somáticas em leite de cabra. Arquivo Brasileiro de Medicina e Zootecnia, v. 53, n. 3, p. 396-400, 2001.

BOULAABA, A.; GRABOWSKI, N.; KLEIN, G. Differential cell count of caprine milk by flow cytometry and microscopy. Small Ruminant Research, v. 97, p. 117-123, 2011.

BRASIL, Ministério da Agricultura. Instrução Normativa $n^{\circ} 37$ de 31 de outubro de 2000. Regulamento técnico de produção, identidade e qualidade de leite de cabra. Diário Oficial da República Federativa do Brasil, Brasília, DF, 8 nov. 2000.

CORREA, C.M.; MICHAELSEN, R.; RIBEIRO, M.E.R.; PINTO, A.T.; ZANELA, M.B.; SCHMIDT, V. Composição do leite e diagnóstico da mastite em caprinos. Acta Scientiae Veterinariae, v. 38, n. 3, p. 273-278, 2010.

GARCIA, V.; ROVIRA, S.; BOUTOIAL, K.; LÓPEZ, M.B. Improvements in goat milk quality: a review. Small Ruminant Research, v. 121, n. 1. p. 51-57, 2014.

GOMES, V.; PAIVA, A.M.M.; MADUREIRA, K.M.; ARAÚJO, W.P. Influência do estágio de lactação na composição do leite de cabras (Capra hircus). Brazilian Journal of Veterinary Research and Animal Science, v. 41, n. 5, p. 339-342, 2004.

MADUREIRA, K.M.; GOMES, V.; CASTRO, R.S.; KITAMURA, S.S.; ARAÚJO, W. P. Análise das metodologias diretas e indiretas para a contagem de células somáticas do leite de cabras. Pesquisa Veterinária Brasileira, v. 30, n. 4, p. 311-316, 2010.

MURRAY, P.R.; BARON, E. J.; PFALLER, M. A.; TENOVER, F. C.; YOLKEN R. H. Manual of clinical microbiology. 7. ed. American Society for Microbiology, Washington, 1999; 365 p.

PAAPE, M.J.; POUTREL, B.; CONTRERAS, A.; MARCO, J.C.; CAPUCO, A.V. Milk somatic cells and lactation in small ruminants. Journal of Dairy Science, v. 84, p. 237-244, 2001. Supplement E.

PAAPE, M.J.; WIGGANS, G.R.; BANNERMAN, D.D.; THOMAS, D.L.; SANDERS, A.H.; CONTRERAS, A.; MORONI, P.; MILLER, R.H. Monitoring goat and sheep milk somatic cell counts. Small Ruminant Research, v. 68, p.114-125, 2007.

PERSSON, Y.; OLOFSSON, I. Direct and indirect measurement of somatic cell count as indicator of intramammary infection in dairy goats. Acta Veterinaria Scandinavica, v. 53, n. 4, p. 15, 2011. e poderiam ser utilizadas por criadores de caprinos que se preocupam com a qualidade do leite e seus derivados.

Apesar do valor da lactose obtido no leite de cabras da raça Toggenburg utilizadas neste estudo estar abaixo do valor preconizado pela legislação, ressalta-se que o mesmo fenômeno já foi anteriormente observado em outros estudos (Correa et al., 2010), evidenciando a necessidade de mais pesquisas envolvendo os limites estabelecidos pelas legislações, uma vez que estes podem muitas vezes não representar as características do leite produzido pelos rebanhos nacionais.

\section{Conclusão}

Com base nos resultados obtidos, pode-se concluir que os parâmetros físico-químicos do leite de cabras sofreram variações de acordo com as raças estudadas, verificadas pela menor concentração de gordura em cabras Saanen; maior celularidade e menor teor de lactose em cabras Toggenburg.

PISANU, S.; MAROGNA, G.; PAGNOZZI, D.; PICCININI, M.; LEO, G.; TANCA, A.; ROGGIO, A.M.; ROGGIO, T.; UZZAU, S.; ADDIS, M.F. Characterization of size and composition of milk fat globules from Sarda and Saanen dairy goats. Small Ruminant Research, v. 109, n. 2-3, p. 141-151, 2013.

PRATA, L.F.; RIBEIRO, A.C.; REZENDE, K.T.; CARVALHO, M.R.B.; RIBEIRO, S.D.A.; COSTA, R.G. Composição, perfil nitrogenado e características do leite caprino (Saanen). Região Sudeste, Brasil. Ciência e Tecnologia Alimentar, v. 18, n. 4, p. 428-432, 1998.

PRESCOTT, S.C.; BREED, R.S. The determination of the number of the body cells in milk by a direct method. American Journal of Public Hygiene, v. 20, n. 3, p. 663-664, 1910.

QUEIROGA, R.C.R.E; COSTA, R.G.; BISCONTINI, T.M.B; MEDEIROS, A.N.; MADRUGA, M.S.; SCHULER, A.R.P. Influência do manejo do rebanho, das condições higiênicas da ordenha e da fase da lactação na composição química do leite de cabras Saanen. Revista Brasileira de Zootecnia, v. 36, n. 2, p. 430-437, 2007.

SAS INSTITUTE. SAS user's guide: statistics. Cary, SAS Institute, 2001. $956 \mathrm{p}$.

SANZ SAMPELAYO, M.R., CHILLIARD, Y., SCHMIDELY, P., BOZA, J. Influence of type of diet on the fat constituents of goat and sheep milk. Small Ruminant Research, v. 68, p. 42-63, 2007.

SILVA, J.N.; ARAÚJO, A.C.; SANTOS, E.P.; HOLANDA NETO, J.P.; ALVES, T.T.L. Parâmetros e determinantes da qualidade físico-química do leite caprino. Revista Verde, v. 6, n. 3, p. 32-28, 2011.

SMITH, M.C.; SHERMAN, D.M. Mammary gland and milk production. In: SMITH, M. C. Goat Medicine. 2. ed. lowa: WileyBlackwell, 2009. p. 647-690.

SOUZA, F.N.; BLAGITZ, M.G.; PENNA, C.F.A.M.; DELLA LIBERA, A.M.M.P.; HEINEMANN, M.B.; CERQUEIRA, M.M.O.P. Somatic cell count in small ruminants: friend or foe? Small Ruminant Research, v. 107, n. 2-3, p. 65-75, 2012.

SUNG, Y.Y.; WU, T.I.; WANG, P.H. Evaluation of milk quality of Alpine, Nubian, Saanen and Toggenburg breeds in Taiwan. Small Ruminant Research, v. 33, n. 1, p. 17-23, 1999. 
VILANOVA, M.; GONÇALVES, M.; OSÓRIO, M.T.M.; ESTEVES, R.; SCHMIDT, V. Aspectos sanitários do úbere e composição química do leite de cabras Saanen. Acta Scientiae Veterinariae, v. 36, n. 3, p. 235-240, 2008.

WANG, L.; REN, C.; YOU, J.; FAN, Y.; WAN, Y.; ZHANG, Y.; WANG, F.; HUANG, M. A novel fluorescence reporter system for the characterization of dairy goat mammary epithelial cells. Biochemical and Biophysical Research Communications, v. 458, p. 783-789, 2015.
ZENG, S. S. Comparison of goat milk standards with cow milk standads for analysis of somatic cell count, fat and protein in goat milk. Small Ruminant Research, v. 21, n. 3, p. 221-225, 1996.

ZERVAS, G., TSIPLAKOU, E.. The effect of feeding systems on the characteristics of products from small ruminants. Small Ruminant Research, v. 101, p. 140-149, 2011. 